\title{
El desarrollo de la viticultura y el consumo del vino en el ámbito cartaginés
}

\author{
Fernando Prados Martínez *
}

\begin{abstract}
RESUMEN ABSTRACT
En el presente trabajo nos acercamos In the present article, we approach al conocimiento de la cultura del vino en el área de Cartago. Para ello, vamos a completar los abundantes testimonios textuales con los datos puramente arqueológicos, que, si bien han sido escasos, pueden proporcionarnos aún bastante

to the knowledge of the wine culture in the Carthage environment. To the great volume of textual classical sources we should add archaeological data from the excavations in Carthage and another Punic sites.
\end{abstract} información si son cotejados con otros provenientes de otras zonas púnicas.

* Universidad Autónoma de Madrid. 
"...Praecepta rusticationis, quae plurima tradiderint Poeni

ex Africa scriptores."

Columela, De Re Rustica, I, 1, 6 .

Hos rei rusticae scriptores nobilitate Mago Carthaginiensis praeterit.

Varrón, Rerum rusticarum libri I, 1, 10.

De estas afirmaciones que se han citado, tomadas de dos de los más destacados agrónomos latinos podemos extraer que la cuna y el lugar donde se inició la ciencia agronómica y donde tuvo un mayor desarrollo fue el ámbito de Cartago. De este modo tenemos que fijarnos más en estas citas que en los vestigios y los datos que se han ido recogiendo desde las investigaciones arqueológicas, los cuales han sido, como veremos a lo largo del trabajo, bastante exiguos y poco significativos. No podemos poner en duda la completa veracidad de tales manifestaciones, sobre todo si tenemos en cuenta el habitual desprecio del mundo grecorromano hacia todo aquello proveniente de Cartago, es decir, del enemigo natural y potencia antagónica en el Mediterráneo. El volumen de fuentes literarias latinas que han menospreciado al enemigo, acusándolo de bárbaro e incivilizado, de envidioso, traicionero, corrupto y homicida de sus propios vástagos, no tiene parangón con aquellas que honraban algunos rasgos de esta cultura como un vehículo de ensalzamiento de Roma, la cual ampliaba su gloria mostrándose como la nueva potencia que asoló la antigua ciudad de Dido, la "reina de los mares».

Fuera de los documentos históricos latinos generalmente imbuidos dentro de las corrientes oficiales de propaganda, gozamos de todo un amplio conjunto de textos que, como ya se ha citado al comienzo, proporcionaron valiosos datos sobre el desarrollo de la agronomía en general, y de la viticultura en particular. En estas fuentes se aceptó siempre el destacado papel del mundo cartaginés y la figura de Magón, como veremos más adelante, como precursor.

\section{INTRODUCCIÓN; PANORAMA GEOGRÁFICO Y EVOLUCIÓN HISTÓRICA DE LA VITICULTURA EN EL ÁREA DE CARTAGO}

La nación que engloba en su completa totalidad el área que durante la fecha de extensión del cultivo organizado de la vid hacia el siglo iv a.C., 
controlaba directamente la Megalópolis de Cartago, es la actual República Arabe de Túnez. Aquí se encuentra la zona que vamos a tratar en este estudio, es decir, la más próxima a la gran capital púnica. Se trata, pues, de un país de contrastes, de tamaño reducido comparado con las naciones vecinas del Maghreb, pero bastante homogéneo geográficamente. Se caracteriza por un relieve bastante moderado, que no supera en ningún caso los $1.200 \mathrm{~m}$ de elevación. Las montañas quedan separadas por amplios y fértiles valles llanos que facilitan enormemente las comunicaciones. Una peculiaridad de la geografía de Túnez es la doble exposición marítima, es decir, la existencia de costa mediterránea al norte (rocosa y accidentada) y el este del pais (con planicies enormes y fértiles que se abren al mar) lo que incide directamente en el clima, pues permite la penetración de masas de aire templado y cálido que provocan que nos encontremos ante una de las regiones norteafricanas con mayor volumen de precipitaciones. La orografía del terreno y el clima originan la presencia en Túnez de tres grandes regiones naturales, bien diferenciadas: el desierto al sur, la estepa, en el centro y al sureste, y el tell, al norte, que es precisamente la que más nos interesa.

La región septentrional del país, denominada geográficamente como tell, será la que presentó en la antigüedad y hasta la actualidad la mayor extensión de cultivo de viñedo. Dentro de la región natural del norte, pues, debemos destacar principalmente dos lugares; por un lado, al este, la Península del Cabo Bon, con sus higueras y viñedos, y al oeste, los fértiles valles del río Medjerda, donde aún hoy destacan los mayores cultivos de Vitis del país.

El cultivo de la viña en Túnez no gozó nunca del desarrollo que tuvo, por ejemplo, el olivo. Hoy día éste último se está transformando en muchas regiones en monocultivo. Por otro lado existen los problemas del regadío, pues no existen suficientes reservas hídricas en el país y además se trata de una nación que tiene unas fuentes de riqueza limitadas.

El cultivo de la vid en Cartago, conocido desde los primeros momentos de la presencia fenicia, no tuvo por el contrario desarrollo hasta aproximadamente el siglo iv a.C., ya durante la hegemonía mediterránea de Cartago, como trataremos con detalle. Esta fecha viene determinada por los análisis polínicos efectuados en la zona de los puertos, donde han aparecido restos de Vitis vinifera domesticada por primera vez (Zeist y Bottema, 1982: 19). De todas formas debemos tener en cuenta la escasez de análisis que se han efectuado en este territorio, aunque la documentación arqueológica material obtenida parece también señalar la fecha de finales del siglo $v$ y principios del Iv a.C. para un mayor desarrollo de este cultivo. 
El mayor volumen de vestigios los tenemos desde el siglo $\mathrm{V}$ a. C., precisamente desde el momento de máxima expansión de Cartago. Tras la batalla de Himera (475-450 a.C.) y el control de gran parte de la isla de Sicilia, se constituyó un territorio cartaginés en el norte de Africa y se comenzaron a realizar viajes, exploraciones y empresas comerciales a larga distancia, de esta manera se diversificaron en gran medida las fuentes de riqueza. Precisamente ya desde este momento tenemos referencias literarias que aluden a las riquezas naturales de Cartago:

"Enfrente de su pais, dicen los cartagineses, hay una isla llamada Kerkena, de doscientos estadios de longitud, pero de poca anchura, donde pueden pasar caminando desde el continente, llena de olivares y viñas".

(Heródoto IV, 195)

De finales del siglo iv se tiene la documentación que ofrece Diodoro de Sicilia, que señaló las riquezas de las tierras que recorrieron los soldados del ejército de Agatocles, el tirano de Siracusa, cuando realizó una incursión en el territorio de Cartago, penetrando por el Cabo Bon. Según el historiador "Agatocles condujo la armada a Megalópolis (Cartago). Todo el pais que hacía falta atravesar estaba repleto de vergeles irrigados por fuentes y canales numerosos, casas de campo bien construidas y pintadas con cal que bordeaban la ruta y mostraban la riqueza... los terrenos estaban cultivados de viñas, olivos y árboles frutales, bueyes, corderos y caballos..." (Diodoro de Sicilia, XX, 8, 2-3-4). Además para el autor "en estos lugares se encuentra acumulada tanta opulencia variada de los propietarios más distinguidos de Cartago, los cuales gustaban de emplear su riqueza en los placeres de la vida".

Medio siglo después, será Polibio quien evocó las «numerosas granjas magnificamente equipadas..." en un texto que hace referencia a la 1 Guerra Púnica, durante la penetración por la misma zona del ejército del cónsul Régulo, en el 256 a.C. (Polibio I, 29, 6-7).

De la lectura de estas fuentes extraemos como el célebre Byzacium de los latinos (hoy región del Sahel Tunecino, al este del país) fue considerado una de las regiones más fértiles. De hecho, sabemos que para proteger las riquezas de toda esta región, los cartagineses prohibieron navegar y comerciar al sur de la Península del Cabo Bon a los romanos, como muestran las cláusulas del Primer Tratado Romano Cartaginés (510 a.C.).

Otra de las pruebas extraídas de referencias textuales clásicas que tenemos para comprobar el volumen y el desarrollo de la agricultura púnica en general y de la viticultura en particular es la del historiador helénico Timeo, el cual señaló cómo "los cartagineses mandaron cortar frutales y 
viñedos de Sicilia y prohibieron plantar otros, para asegurarse asi el monopolio" (de Pseudo Aristóteles, De mirabilus auscultationibus, 100; (citado por Gsell, 1918, IV: 20).

Todo parece indicar que los cartagineses abandonaron el cultivo de cereales en su propio entorno, ya que disponian de sus propias posesiones territoriales que funcionaban como auténticos graneros. Estas regiones fueron Sicilia, Cerdeña y Libia. De la documentación obtenida de las citas de Polibio, se aprecia como el mundo púnico africano estaba dividido en dos zonas, con diferentes cultivos: por una lado el área próxima a Cartago, con gran desarrollo de la arboricultura y el viñedo, y por otro, la zona de Libia, donde se desarrolló el cultivo cerealístico.

Otras citas hacen alusión al consumo del vino en el mundo cartaginés, como aquella de Clinias el Ateniense, personaje de uno de los diálogos de Platón que suscribió una prohibición cartaginense contra el consumo de vino por ciertas clases sociales como los soldados en campaña, los magistrados y jueces durante las sesiones, los capitanes de barco, las parejas que deseaban procrear, los ciudadanos durante las horas del día y todos los esclavos (Platón, Leyes, $674 \mathrm{~A}$ ). Esta misma prohibición es citada por Aristóteles (Económica, I, V, 2, 1344).

Tras la toma de Cartago por los ejércitos romanos en el 146 a.C., se produce una gran revolución para los tratadistas romanos, al conocer la agricultura púnica y los tratados de agronomía escritos por sabios cartagineses. Para algunos de estos tratadistas este descubrimiento supuso algo asi como el conocimiento de los textos filosóficos griegos. La tradición siempre vinculó la agricultura púnica como una continuación de la fenicia, sin tener presente el propio sustrato beréber originario. Para otros autores clásicos, la agricultura púnica no tuvo tal desarrollo; este el caso de Cicerón, que afirmó que el verdadero sustento de los cartagineses fue siempre el comercio marítimo y que probablemente Cartago encargó a otros la producción de cereales, además de tener una mano de obra servil en el campo, de origen extranjero. Esta idea es criticable, sobre todo a partir de unos hallazgos arqueológicos tales como la aparición de algunas villas suburbanas en el entorno de Cartago que sin duda fueron controladas por grandes señores, miembros de una clase aristocrática que habitaba habitualmente en Cartago y para los que Magón elaboró su tratado.

El concepto del mar, de la navegación y del comercio caminó unido siempre a Cartago y desde luego es difícil evitar pensar que fue esta la verdadera fuente de riqueza del imperio cartaginés. Cicerón llegó a afirmar que " nada ha contribuido más a la lenta decadencia y la caída de Cartago y Corinto que los viajes en todas las direcciones de sus ciudadanos, que no 
se detuvieron a cultivar sus campos.." (De Re Publica). La riqueza agrícola de Cartago, por el contrario de las afirmaciones de Cicerón, debió tener gran envergadura, ya que fue clave en la recuperación económica de la ciudad tras las Guerras Púnicas, periodos en los que tanto la navegación como el comercio a larga distancia fueron completamente inexistentes por el cumplimiento de las estipulaciones y las cláusulas de los tratados de paz.

En época romana son muy numerosas las referencias al vino de esta región y a los cultivos. Parece ser de todas formas que el vino tunecino no gozó de demasiada fama en Roma, donde se prefirió el vino de Italia, de Hispania y sobre todo de Grecia. A Roma le interesó mucho más promover y potenciar el cultivo de cereales en esta zona, especialmente el del trigo. La ciudad de Cartago quedó desierta desde su destrucción en el 146 a.C. hasta la fundación de César de la Colonia lulia Karthago en el 44 a.C. Las excavaciones de las estructuras y niveles de la fase imperial en la colina de Byrsa, centro neurálgico de la ciudad, han presentado además más de un $80 \%$ de ánforas importadas que contenian vino, lo que entronca con 10 anteriormente comentado, es decir, la escasa producción y la baja calidad del vino cartaginés en las fases altoimperiales que hizo que las familias de colonos de origen itálico que ocuparon la nueva colonia, tuvieran que adquirir el vino de fuera.

Según fue avanzando el Imperio, la decadencia creciente de la agricultura en la Península Itálica (Albertini, 1955: 57) provocó la escasez de vino en Italia, lo que sin duda influyó en un mayor desarrollo de la viticultura en Túnez, donde se alcanzó un equilibrio en los cultivos de viñedo, trigo y olivo. Este desarrollo de la viticultura en época Tardorromana quedó bien reflejado en mosaicos con temas campestres que aparecen en las uillae suburbanas cercanas al río Medjerda (como en los mosaicos de Tabarka). En época Bizantina se mantuvo el desarrollo de la viticultura y el consumo de vino en la zona hasta la prohibición a partir de la conquista árabe, desde el siglo VII, de su consumo y elaboración, según prescripciones coránicas. La prohibición además se radicalizó, con la destrucción total de los viñedos, bajo los auspicios del lider almohade Ibn Tumart en 1118.

Así, durante toda la época medieval, la superficie del viñedo quedó reducida al mínimo, apareciendo tan sólo algunos ejemplares en jardines privados, dedicándose su fruto al consumo en la mesa. Tan sólo la colonización europea y el protectorado francés en Túnez desde 1882, sumado a la crisis de la phylloxera en Europa que redujo el número de viñedos, hizo que se volviese a cultivar en Túnez. Así, desde finales del siglo xIX, Túnez se convirtió en productor de vino (el segundo productor africano, tras Argelia, donde el cultivo también fue incluido por los europeos) alcanzando 
su máximo desarrollo en los años treinta del siglo $x x$, antes de la gran crisis de 1936, con la llegada de la phylloxera a este territorio y la de la gran sequia de 1945 (durante la que se redujo el área de cultivo a 23.000 hectáreas). Desde los años sesenta se ha recuperado enormemente el cultivo, ocupando en la actualidad una superficie superior a las 50.000 hectáreas, repartidas como en la antigüedad en el valle del Medjerda y en la Península del Cabo Bon.

\section{DE AGRICULTURA CARTAGINESA: EL TRATADO AGRONÓMICO DE MAGÓN COMO PARADIGMA}

La clave para el conocimiento teórico de la agronomía cartaginesa es el tratado de Magón (fechado hacia finales de siglo IV y principios del III a.C.) que se conoce a partir de las traducciones realizadas por griegos y latinos. Dichas traducciones que se llevaron a cabo desde el momento mismo de la conquista, bajo los auspicios de Catón, supusieron un aporte fundamental para la agronomía romana, que alcanzó un gran desarrollo y esplendor. La obra de Magón tuvo una gran envergadura y sus veintiocho libros desde luego se acercaron bastante a una enciclopedia sobre el mundo agrícola, al que se acercó desde numerosas perspectivas. La importancia de la obra radica en las numerosas traducciones que de ella se llevaron a cabo y en la cantidad de citas de todos los agrónomos de la antigüedad como Varrón, Columela, Plinio, Gargilus Martialis y el autor de las Geoponica.

La obra se conoce fundamentalmente a través de las continuadas citas de dos de los más grandes agrónomos latinos, esto es, Varrón y Columela. Para el primero, la obra de Magón fue la suma de todos los conocimientos $y$, probablemente, esa fue su auténtica naturaleza, es decir, una compilación de datos recogidos desde un conocimiento de la tradición agronómica desarrollada en el entorno de Cartago desde época fenicia, bien oral o escrita. Varrón prestó una admiración extrema a este probable miembro culto de la nobleza púnica afirmando:

"Uerum tamen ut carthaginiensem Magonem rusticationis parentem maxime veneremur"

\section{Varrón (Rerum Rusticarum libri I, 1.13)}

Magón fue, según nos acercan estos autores clásicos, el creador de la agronomía en sentido amplio, incluyendo aspectos tales como los cultivos, la economía rural, la gestión mercantil de los productos agrícolas, las herramientas, la mano de obra e incluso alguna receta de cocina. 
Evidentemente Magón no los inventó, sino que fue el primero capaz de realizar una obra de síntesis y en ver la agronomía como una disciplina autónoma (Martin, 1971: 45).

La obra de Magón se recoge en veinticinco citas de las cuales dos hacen alusión a los modelos de explotación del suelo, una al almacenaje de los cereales, cinco tratan aspectos relacionados con los animales de tiro (prescripciones sanitarias, elección de los bueyes, castración de los mismos y dos sobre el tiro con mulas) otras tres recogen conocimientos sobre otras explotaciones del mundo rural, como la apicultura y elaboración de la miel. El resto de las citas conocidas de Magón se basan en la arboricultura y la viticultura, lo que nos es de gran interés. La mayor parte de estas citas las realiza Columela (De Re Rustica, III, 12, 5 y 3,15 , 4-5; IV 10,1; V 5,4 y XII) y otras también vienen de textos del agrónomo Palladio.

Algunos datos fundamentales sobre el cultivo de la vid aparecen en la obra de Columela. En dichos escritos se menciona cómo ha de ser la plantación de las viñas (De Re Rustica, III, 10, 3). También el agrónomo Virgilio en su obra "Geórgicas" utilizó numerosos datos de la obra de Magón, aunque los tomó como propios y tal fue la admiración que por el cartaginés tuvo Columela que descubrió a Virgilio señalando que sus escritos sobre la protección de la viña habían sido tomados de Magón:

"Hi uidentur, ut Mago prodit, et aquas hiemis

et uapores aestatis propulsare radicibus;

quem secutus Uergilius tutan semina et muniri sic praecipit...”

Columela (De Re Rustica, III, 15, 4)

La utilización de la obra de Magón quedó pues patente, a pesar de que Virgilio lo negase. Además existe un dato concluyente, y es el curioso vacio existente en relación al ganado porcino, ya que no se realiza ninguna alusión al cerdo en las "Geórgicas" de Virgilio, algo que desde luego es extraño en un tratado agronómico latino, a no ser que copie numerosos aspectos de otro de procedencia semita, como el de Magón, propio de una cultura que no consumia este animal. El tratado de Magón se concibe para un público culto, para una clase de grandes propietarios de terrenos fértiles en los alrededores de Cartago, que mediante un sistema esclavista se ocuparon de la viticultura y la arboricultura. La mano de obra conformada fundamentaimente por prisioneros de guerra trajo consigo numerosas revueltas serviles y una sensación continua de inestabilidad. Magón aconsejó a estos grandes propietarios que abandonasen la ciudad y que se trasladasen a vivir a sus villas rurales, de manera que pudiesen controlar directamente la producción y el desarrollo de las actividades agrícolas. 
Conocemos también, y una vez más gracias a Columela, que Cartago había tenido otros tratadistas sobre Agronomía "praecepta rusticationis plurima tradiderunt Poeni ex Africa scriptores" (De Re Rustica, I, 1, 6) así, Magón pudo ser simplemente un gran recopilador de datos y de tradiciones. Otras referencias literarias sobre el cultivo de la vid en Cartago vienen de mano de Polibio, que menciona diferentes tipos de cepas, los cuidados que daban a las plantas enfermas, la protección del racimo, las diferencias entre vino joven y vino nuevo y la conservación del vino durante su transporte marítimo, que relaciona además con el desarrollo de las soluciones de los problemas de la exportación de productos por parte de los cartagineses.

Otro interesante dato que extraemos de la documentación escrita es el escaso interés por el cultivo de cereales, lo que podemos aceptar sin duda para el ámbito de Cartago durante la época púnica, y no tanto ya durante la conquista romana. Curiosamente de las citas del texto de Magón, tan sólo una hace alusión al cultivo de los cereales, mientras que la viña adquiere una mayor importancia. Sabemos que el imperio cartaginés tuvo otras zonas destinadas para estos cultivos de secano y que reservaba su entorno más próximo para otros tipos de plantaciones como la vid o los árboles frutales (donde se encontraría el célebre vergel de Amílcar, en Megara, como cita Gustave Flaubert en su novela Salammbô, editada en 1862).

\section{LA VITICULTURA Y EL CONSUMO DE VINO EN CARTAGO A LA LUZ DE LOS DATOS ARQUEOLÓGICOS}

La viticultura y el consumo del vino en el mundo cartaginés y especialmente en el ámbito de la ciudad de Cartago han dejado, al menos aparentemente, escasos datos que nos puedan servir hoy para reconstruir la totalidad de su desarrollo. Evidentemente, el volumen de información recuperada no es comparable de forma alguna a la cantidad ingente de datos obtenidos desde la lectura de las fuentes, como ya hemos podido apreciar anteriormente. De todas formas, la presencia de algunas cerámicas de transporte (no de consumo, ya que es difícil determinar una vajilla púnica especial para el consumo del vino) exportadas a diversos lugares del Mediterráneo Occidental como la costa catalana (Asensio et alii, 1998: 66), las excavaciones arqueológicas en algunas villas rurales del entorno de Cartago y el cotejo con otros hallazgos materiales de la órbita púnica como los lagares exhumados en el poblado de Las Cumbres (Pto. de Sta. María, Cádiz) han proporcionado datos para poder hablar de una «cultura del vino" púnica, que desde luego, no es comparable con la desarrollada en el mundo del Egeo y la Magna Grecia o por los etruscos 


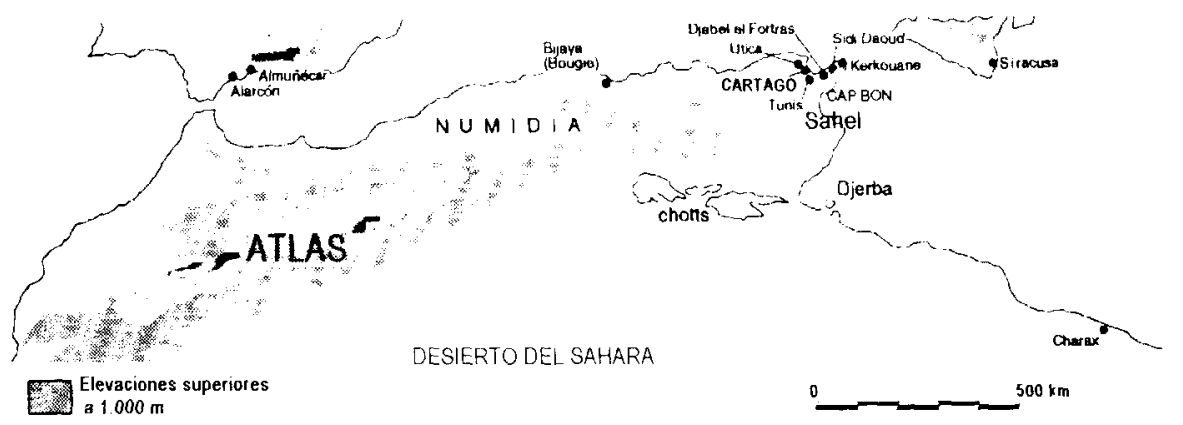

Fig. 1. Hallazgos de vitis silvestre en las costas del Mediterráneo Occidental.

(Tomado de J.A. Greene, 1996, 312).
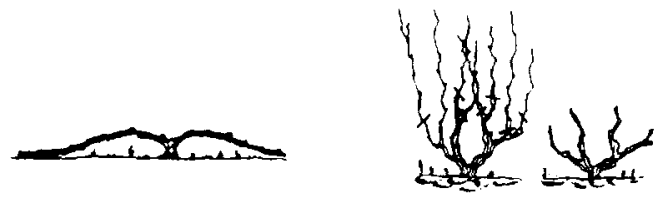

Fig. 2. Especies cultivadas en el ámbito cartaginés. (Izq. vitis stratae; dcha. vitis capitatae).

Los primeros testimonios de los que se tiene referencia en Cartago de consumo de vino vienen de las excavaciones antiguas en las tumbas denominadas "arcaicas" de la zona de Byrsa, de las que se recuperaron algunos vasos exóticos para beber vino de procedencia griega (kotyles del siglo VIII-VII a.C.) El hecho de no aparecer una vajilla propiamente púnica (Morel, 1998: 34) para el consumo del vino hace que ese consumo del mismo supusiese un acto puramente destinado a celebraciones puntuales como los funerales o a otro tipo de actos a los que tendrían acceso tan sólo las clases elevadas, es decir, aquellas que dirigieron las empresas comerciales de ultramar y que controlaron el senado de Cartago.

Las residencias rurales que se han excavado en Túnez (Fantar, 1984: 4; Fantar, 1985: 13 y ss.) presentan esquemas bipartitos, con la zona residencial, que estuvo ocupada por el rico terrateniente y su familia, a un lado, y la zona de uso industrial, una clase de "pars rustica" con almazaras y con pithoi y dolia encastrados en el suelo y depósitos revestidos de opus signinum para contener vino y aceite. Dos de estas villas, han sido 

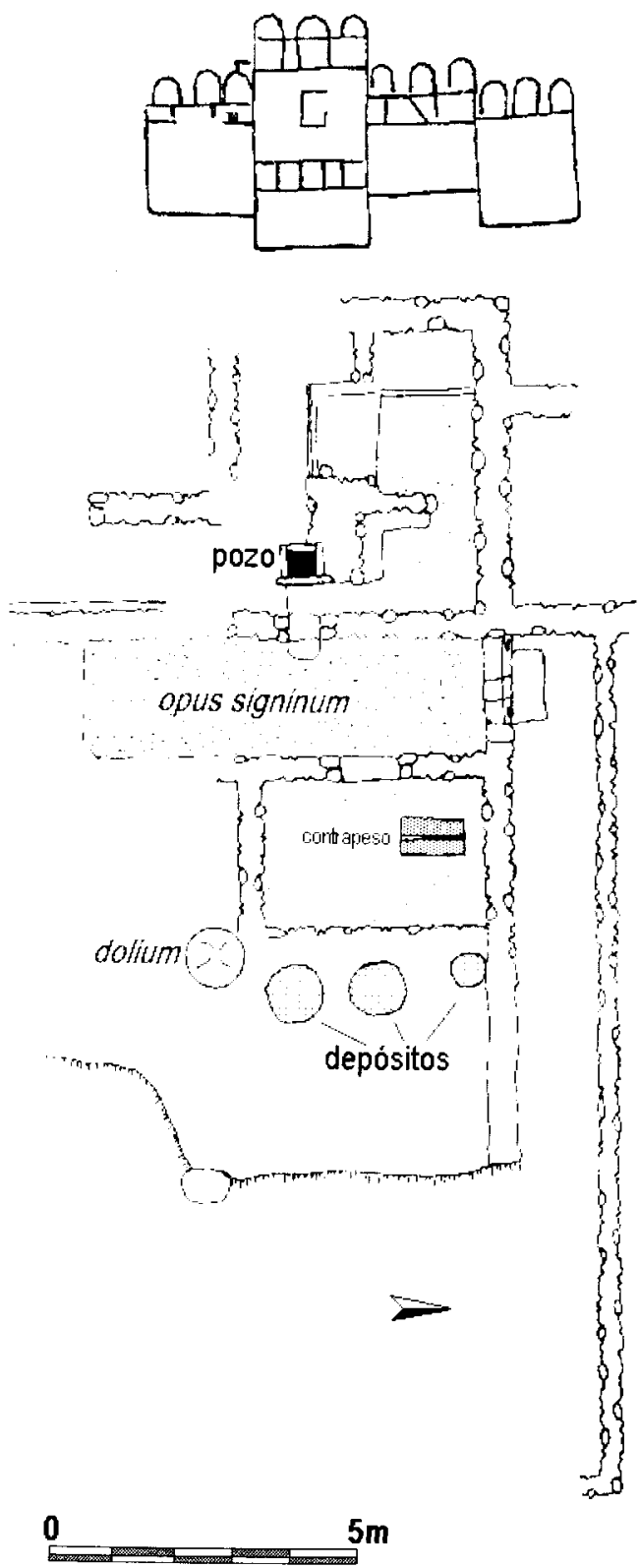

Fig. 3. Pintura de una casa rural púnica en una tumba de Sidi-Mosbah, Cabo Bon (arriba). Planta de la villa de Gammarth, en los alrededores de Cartago (abajo). 

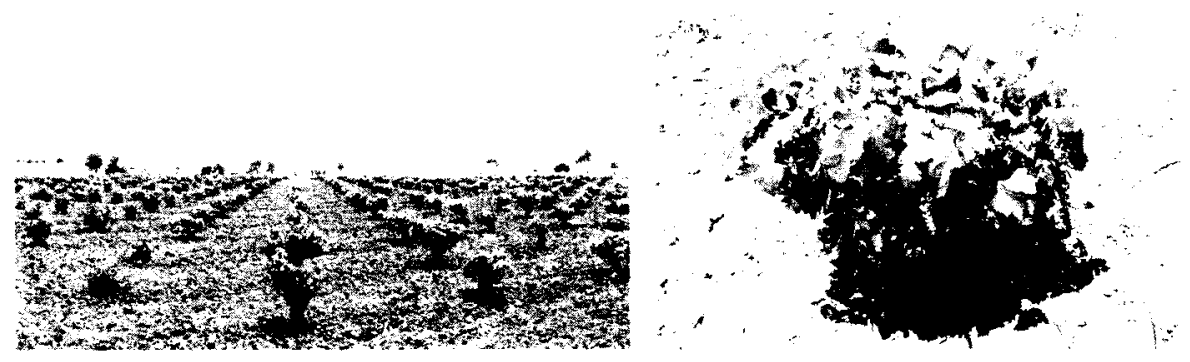

Fig. 4 (1). Aspectos diversos del cultivo de la Vitis capitatae en el Cabo Bon (Túnez).
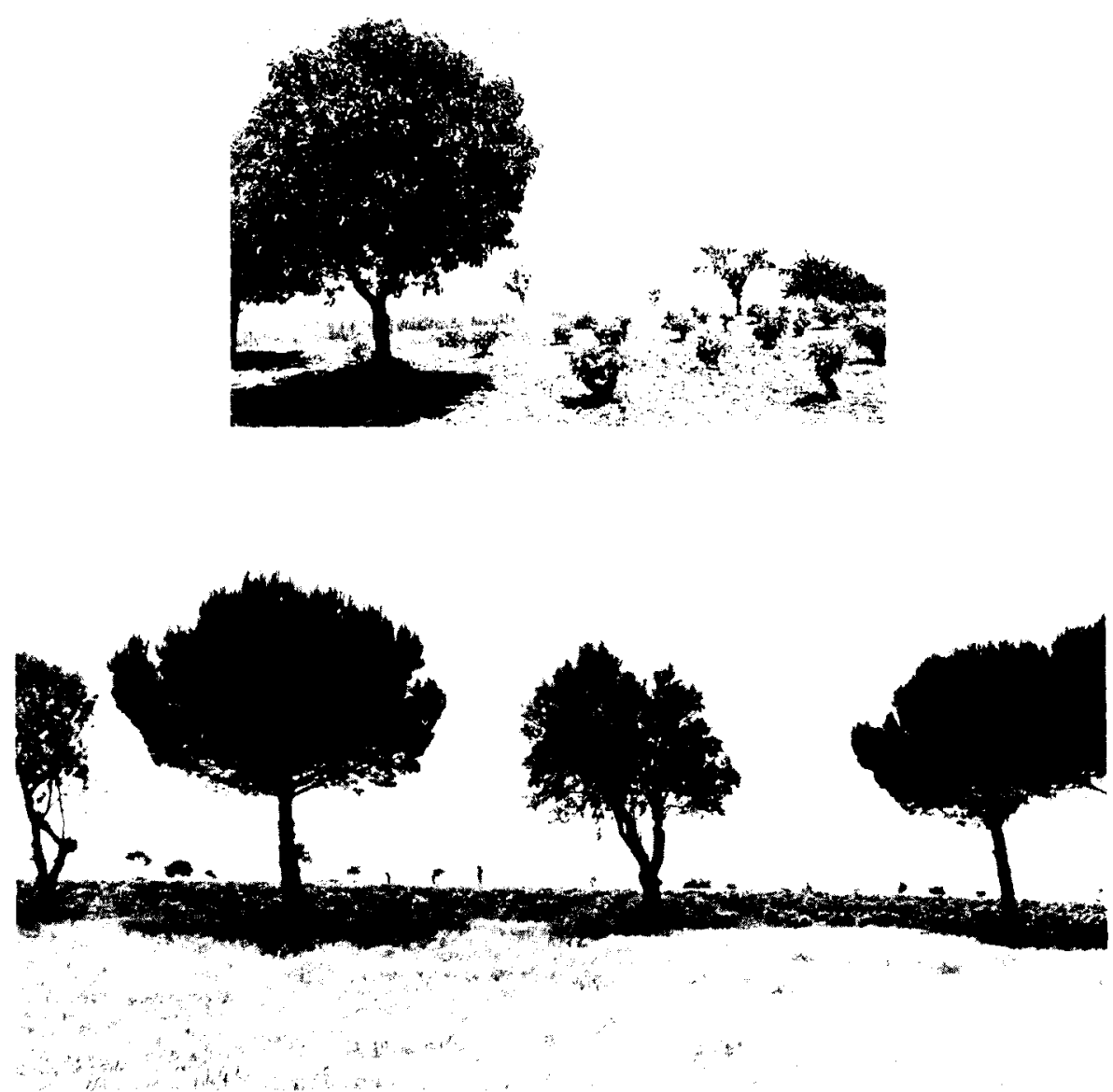

Fig. 4 (2). Viñedos del Cabo Bon junto a higueras (arriba) y cultivo combinado de cereal (trigo) y Vitis vinifera (abajo). 

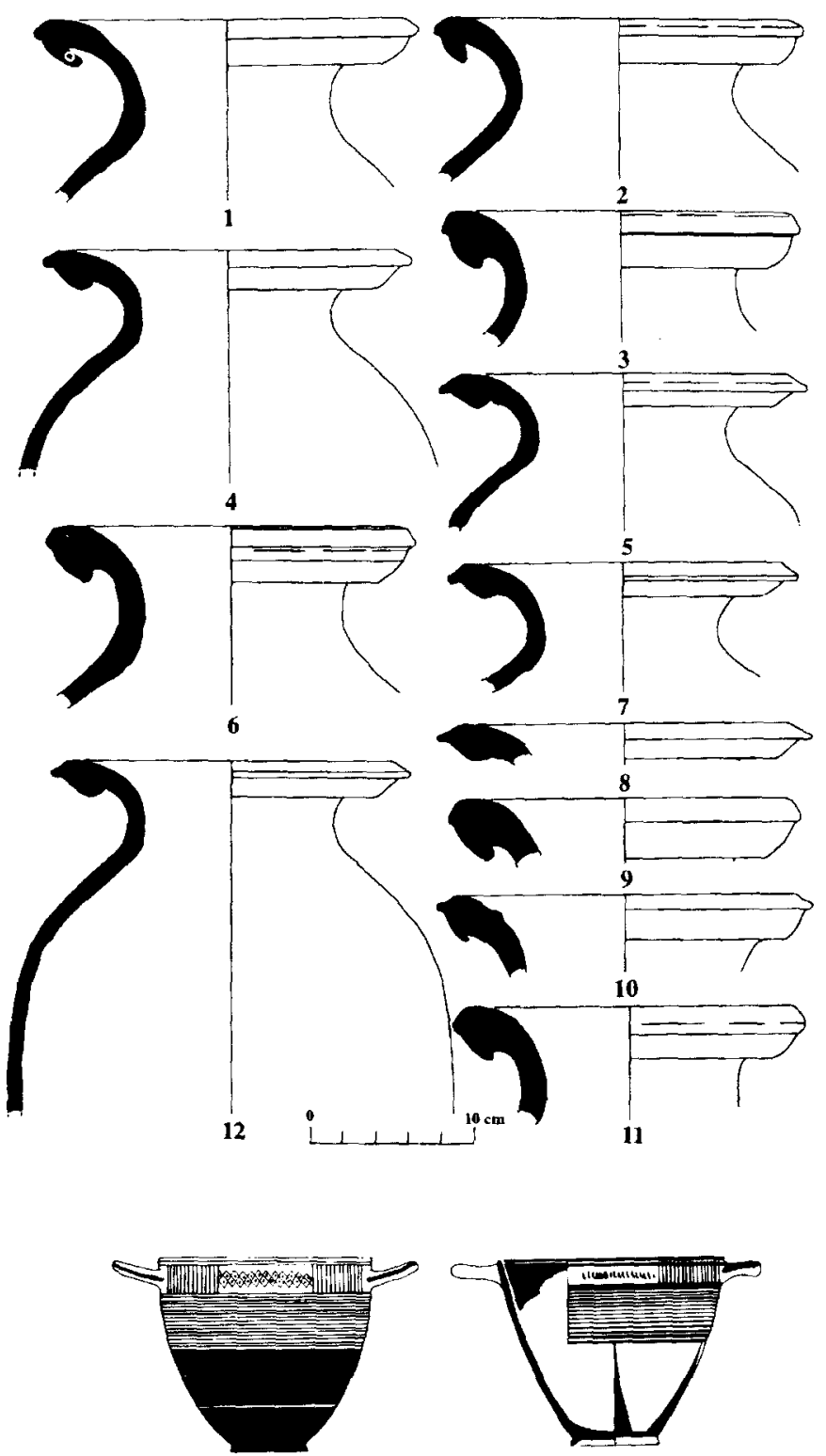

Fig. 5. Ánforas de Cartago aparecidas en yacimientos de la costa catalana (Según Asensio et alli, 1998, 70) (arriba). Abajo, Copas protocorintias para el consumo de vino (izq. Almuñécar, Tumba 19, 720-690 a.C.; dcha. Tumba 195 de Byrsa, 690-650 a.C.) (Según J.A. Greene, 1996, 318). 
excavadas en Gammarth, muy cerca de Cartago. La Villa de Baie des Singes que fue prácticamente destruida por una máquina excavadora, proporcionó datos sobre este tipo de asentamiento rural a las afueras de la capital. Se recuperaron una serie de estancias de planta rectangular, con presencia de hornos de pan y ánforas de tipo grecoitálico (que fechan el abandono de la vivienda en torno a los primeros años del siglo II a. C., al final de la Segunda Guerra Púnica) con cisternas y piletas recubiertas de hormigón hidráulico (Fantar, 1985: 14).

La otra villa rural próxima a Cartago es la de Gammarth, que fue hallada de forma fortuita en 1967. La superficie total del edificio es de $200 \mathrm{~m}^{2}$ (Fantar, op. cit. 14 y ss.) y presenta un plan bipartito, con un área residencial, con sala de baño y estancias abiertas a un patio con columnas y ricos capiteles, y un sector industrial, de producción y almacenamiento de productos agrícolas. Presenta unas estancias a diferentes alturas y de nuevo unos espacios con plantas rectangulares utilizados como almacenes. Otras estructuras exhumadas han sido pozos circulares y piletas recubiertas de opus signinum y lo que el excavador ha interpretado como una almazara, por la presencia de contrapesos. Asimismo, el edificio pudo estar dedicado también a la producción de vino, como se ha indicado (Fantar, op. cit., 21) por el tipo de contenedores encastrados en el pavimento y por las piletas. Por otro lado, las prensas, que estarían realizadas en madera como en época romana, no se han conservado. La última utilización del edificio fue a mediados del siglo ॥ a.C. y para su excavador pudo ser destruido por la incursión de Escipión Emiliano en el 146 a.C.

Las dimensiones de los edificios, la tipología de las plantas y el carácter industrial de los mismos nos asemejan estas estructuras con las que fueron excavadas en 1991 en una ínsula del Poblado de Las Cumbres, próximo al Castillo de Doña Blanca (Puerto de Santa María, Cádiz) y fechadas en el siglo III a.C. (Ruiz Mata y Pérez, 1995: 106). En este caso del sur de la Península, se han detectado estructuras claramente relacionadas con la producción de vino como son dos lagares con piletas similares a las de Gammarth, colocadas a diferentes alturas para el pisado de la uva y la conducción del mosto mediante pequeños canales. En el caso gaditano, las piletas estaban recubiertas también con opus signinum en el interior y aparecieron junto a ellas unas estructuras circulares para la fermentación del mosto.

Otros testimonios arqueológicos del desarrollo de la viticultura en el mundo púnico los tenemos en el ámbito de las necrópolis, donde han aparecido una serie de elementos relacionados como las pinturas parietales (donde se representan racimos de uva y espigas de cereal) y los restos de frutos en 


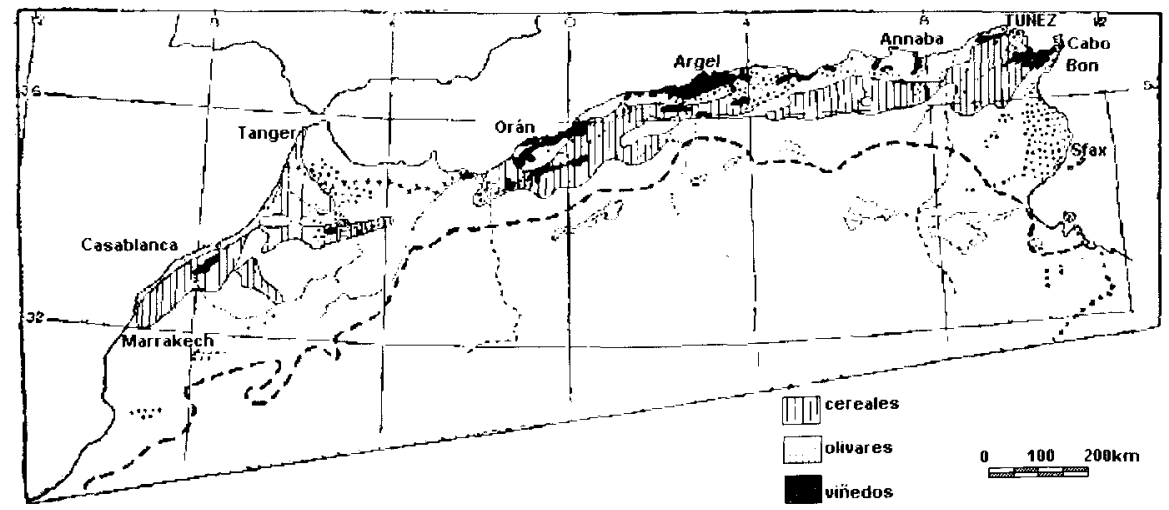

Fig. 6. Principales cultivos norteafricanos (actualizado a partir de Despois, 1964, 370).

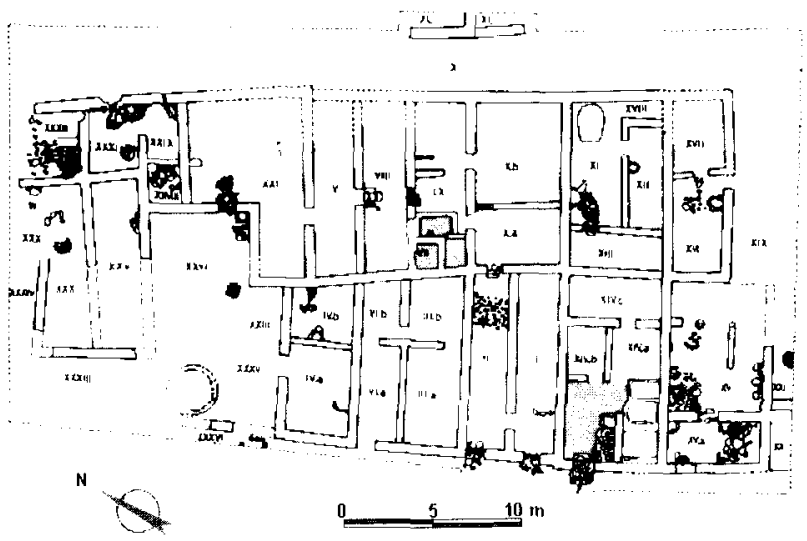

Fig. 7. Poblado de las Cumbres (Pto. de Sta. Maria, Cádiz). Viviendas y zonas industriales; tramados, los dos lagares (según Ruiz Mata y Pérez, 1995, 110).

terracota que han aparecido formando parte de las ofrendas a los difuntos. Otros restos iconográficos han aparecido grabados, esculpidos y pintados, como en las estelas del tofet de Cartago, donde aparecen aperos de labranza y plantas tales como palmeras, olivos, granados y por supuesto, viñas.

Un problema es que apenas se han realizado análisis de contenidos en las ánforas (Greene, 1996: 317) aprovechando las resinas para efectuar cromatografías (teniendo en cuenta que aquellas ánforas que presentan resinas no han contenido jamás aceite, pues éste las disuelve) y tampoco 
análisis de taninos (sustancias astringentes de carácter vegetal que penetran en las arcillas porosas y que se detectan magnificamente). Así tan sólo tenemos una información parcial de los contenedores, con las tipologías y con algunas marcas, generalmente de alfarero y con algún que otro antropónimo (como Aris o Magón) que bien podría aludir a algún productor. Por las tipologías y por la comparación con otras ánforas sobre las que sí se han podido efectuar analíticas, se sabe que estarian preparadas para el transporte interno y de ultramar, y que contendrían generalmente cereales, aceitunas, vino, aceite y miel.

Como indica Fantar (1996: 121) es probable que la escasez de restos epigráficos y de estelas en santuarios con alusión al vino pueda ser por causa del probable desprecio de los cartagineses hacia los trabajos del campo, efectuados por esclavos y que estarían totalmente devaluados para las clases sociales elevadas. Ahi puede estar la razón de las escasas imágenes de viñas en las estelas neopúnicas de Cartago y la no aparición de referencias en las monedas, al contrario de otras acuñaciones de la órbita púnica, como las de la ciudad de Lixus.

Por otro lado, aún queda mucho por hacer dentro de este campo, ya que han sido detectadas en prospecciones para la Carta Arqueológica de Túnez, la cual se encuentra actualmente en preparación por parte de un equipo del Instituto Nacional de Patrimonio, un conjunto de instalaciones junto a la frontera con Argelia talladas en la roca y que parecen lagares del tipo a los definidos como preindustriales por Greene (1996: 322). Negar la existencia de una cultura del vino en una sociedad mediterránea como es la cartaginesa, es complicado, sobre todo si tan sólo nos apoyamos en la diferencia existente entre el volumen de información literaria y la estrictamente arqueológica. Una vez más podemos jugar con los «argumentos de silencio", es decir, el hecho de que no aparezca un amplio volumen de datos arqueológicos no significa la inexistencia de los mismos.

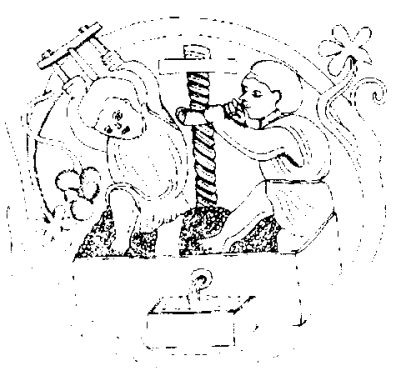

Fig. 8. Prensa de uva, de un mosaico de Tiro (según Frankel, 1999, 140). 


\section{CONSIDERACIONES FINALES}

No podemos negar la existencia de una cultura del vino en Cartago, cuando la máxima figura conocida de la agronomía en la antigüedad, de origen cartaginés, se interesó prioritariamente en el cultivo de la viña. De nuevo nos encontramos ante la desigualdad de los textos con relación a los restos exhumados por las intervenciones arqueológicas. Cartago, el centro de comercio, el cruce de caminos entre Oriente y Occidente, el lugar por donde circularon gran parte de los productos procedentes del Mediterráneo Oriental y del Egeo, tuvo que tener, por fuerza, una cultura del vino, tanto desde la perspectiva de la producción, como desde la del consumo.

Por otro lado, el modelo de intervención que se ha llevado a cabo en el área tunecina, ha dado prioridad a los grandes conjuntos arqueológicos conocidos, emprendiendo proyectos de investigación en yacimientos señeros como Cartago, desde los años setenta, con equipos conformados por arqueólogos daneses, franceses, ingleses y norteamericanos, dentro de un proyecto financiado por la U.N.E.S.C.O. o en la ciudad púnica de Kerkouane, en el Cabo Bon, nombrada patrimonio del Mediterráneo y excavada desde hace lustros por un equipo formado por miembros del Instituto de Patrimonio Tunecino. Así pues, el conocimiento de las villas rurales cercanas a la gran urbe púnica, ha estado determinado por factores meramente casuales. La fortuna ha deparado la aparición de estas instalaciones agropecuarias, que han sido excavadas con premura, ya que ocupaban terrenos que iban a ser edificados. También la tremenda transformación de la ciudad púnica tras la conquista romana hizo que se perdieran, sin duda, numerosos testimonios. Si tan sólo podemos estudiar unos mínimos restos arquitectónicos de lo que fue la gran polis hegemónica en Occidente durante 350 años en las estructuras conservadas en los llamados barrios de Anibal, en Byrsa, o de Magón ¿qué puede haber llegado hasta nosotros de las villas del extrarradio? En la actualidad, la propia urbanización desigual del entorno de la planicie de El Mersa, Megara, los viñedos de Soukara y la ciudad de Túnez y su crecimiento descontrolado ha provocado también una inmensa destrucción de datos.

De todas formas, desde la lectura pormenorizada de las fuentes, desde el análisis de las publicaciones de las excavaciones efectuadas y desde la comparación con otras estructuras de similares caracteristicas por el Mediterráneo, podemos reconstruir al menos, en parte, el panorama agrícola de los alrededores de Cartago y en particular, el del cultivo del vino. También la observación de los terrenos agrícolas de las planicies del Medjerda o del Cabo Bon en la actualidad nos puede dar la pista. Se trata 
de un paisaje eminentemente olivarero y cerealístico que da paso en las zonas más fértiles a grandes extensiones de viñedo, acompañadas de cuando en cuando de alguna especie de pino mediterráneo y de higuera, que suponen el único cobijo de un sol que calienta tremendamente en verano. Un paisaje seguramente muy similar al que pudieron ver las tropas de Agatocles de Siracusa durante su intento de conquista.

Los datos sobre el consumo de vino en cambio, son exiguos, pese a que se detecta un cierto comercio anfórico en los puertos de Cartago, con productos importados, así como también con la aparición de ánforas cartaginesas probablemente contenedoras de vino en puntos de la Península Ibérica, Cerdeña y sobre todo Sicilia, en cronologías del siglo IV, III y II a.C. También la documentación escrita una vez más es clarificadora: del tratado de Magón extraemos una magnífica receta para la confección de un vino dulce, elaborado a partir de uva pasa, que tendría después gran aceptación en el mundo romano; se trata del célebre passum, algo similar al vino de postre que consumimos hoy, conocido con el nombre de la variedad de uva con la que se confecciona, la Pedro Ximénez.

Son tantos los datos que manejamos sobre el vino cartaginés, que no podemos negar su consumo por el hecho de que no se haya identificado una vajilla propia para tales efectos dentro de los tipos y formas cartaginesas. Esperamos que con el avance de la investigación sobre el mundo púnico, podamos extraer en los próximos años más datos sobre el vino en esta época, aunque sea de forma indirecta, en un país árabe que, sin embargo, se enorgullece de la calidad del vino que produce hoy dia.

\section{BIBLIOGRAFIA}

ACOUARO, E., AUBET, M. ${ }^{a}$ E. y FANTAR, M.H. (1993): Insediamenti fenici e punici nel Mediterraneo occidentale. Roma.

ALBERTINI, E. (1955): L'Afrique Romaine. Argel.

Alvar, J. y G. WAGNER, C. (1988): "La actividad agricola en la economia fenicia de la Península Ibérica". Gerión 6, Universidad Complutense. Madrid; págs. 169-185.

AMOURETTI, M.C. (1988): "La viticulture antique méditerranéenne et ses rapports avec la vinification". El Vi a l'Antiguitat. Economia, Producció i Comerç al Mediterrani Occidental. Actas I/ Col-loqui Internacional d'Arqueologia Romana. Badalona; págs. 15-27.

ASENSIO, D., DEVENAT, L. y SANMARTi, J. (1998): "Les impotacions amforals d'origen púnic a la costa de Catalunya en època Tardorepublicana". El Vi a l'Antiguitat. Economia, Producció $i$ Comerç al Mediterrani Occidental. Actas // Col-loqui Internacional d'Arqueologia Romana. Badalona; págs. 66-73.

Aubet SemmleR, M. ${ }^{a}$ E. (1997): (ed.) Los fenicios en Málaga. Universidad de Málaga. Málaga. BARRECA, F. (1986): La civiltà fenicio-punica in Sardegna. Sassari.

BLANCO, J.L. y ROUGgeAU, M. (1999): “Técnicas para la elaboración del vino". El vino en la Antigüedad Romana. Simposio Arqueologia del Vino (Jerez, 1996). Madrid; págs. 117-128.

CARRILERO MILLÁN, M. y LÓPEZ CASTRO. J.L. (1994): «Ciavieja, un asentamiento de época púnica en el poniente almeriense". El mundo púnico, Historia, sociedad y cultura. Murcia; págs. 251-268. 
CECCHINI S.M. (1986): "Problemes et aspects de l'agriculture carthaginoise". Histoire ef Archéologie de l'Afrique du Nord (Actes III Colloque International, Montpellier, 1985). París; págs. 108-110.

Celestino Pérez, S. (1999): (ed.) El vino en la Antigüedad Romana. Simposio Arqueologia del Vino (Jerez, 1996). Madrid.

CINTAS, P.

- 1970: Manuel d'Archeologie Punique I. Paris.

- 1976: Manuel d'Archeologie Punique II. París.

Chelbi. F. (1992): Ceràmique à vernis noir de Carthage. Túnez.

DespoIs. J. (1964): L'Afrique Blanche 1. L'Afrique du Nord. París.

FANTAR, M.H.

- 1975: «Le probleme de l'eau potable dans le monde phénicien et punique: les cisternes." Cahiers Tunisiennes XXIII. N. ${ }^{\circ}$ 89-90. Túnez.

- 1984: "À Gammarth avant la conquête romaine". Histoire et Archéologie de l'Afrique du Nord (Actes I Colloque I International, Perpignan 1981). París; págs. 3-19.

- 1985: Kerkouane, cité punique du Cap Bon (Tunisie) Vol. 2. Túnez.

- 1996: “De l'agriculture à Carthage". L'Africa Romana. Atti del XII convegno di studio. Olbia; págs. 113-121.

- 1998: Kerkouane. Cité punique au pays berbère de Tamezrat. Túnez; págs. 8-9

FRANKEL, R. (1999): Wine and oil production in Antiquity in Israel and other Mediterranean Countries. Sheffield.

Gómez Bellard, C. (1986): “Asentamientos rurales en la Ibiza Púnica». Los fenicios en la Península lbérica. Sabadell; págs. 177-192.

GOMEZ BELLARD, C y GUERIN, P. (1994): "Testimonios de la producción vinícola arcaica en L'Alt de Benimaquia (Denia)". Iberos y Griegos, lecturas desde la diversidad, Simposio Internacional (Ampurias 1991). Huelva Arqueológica XIII, 2. Huelva; págs. 9-31.

GREENE, J.A. (1996): "The Beginnings of grape cultivation and wine production in Phoenicean / Punic North Africa». En Mc Govern, P.E., Fleming, S.J. y Katz, S.H. (Eds.) The Origins and ancient history of Wine. Amsterdam; págs. 311-322.

GSEll. S. (1918): Histoire Ancienne de l'Afrique du Nord, 4 Vols. Paris.

HEURGON, J. (1976): “L'Agronome Carthaginois Megon et ses traducteurs en latin et en grecque". Comptes Rendus de l'Academie des Inscriptions et Bonnes Lettres. París; págs. 441446.

LEVAdoux. L. (1961): La vigne et sa culture. París.

LIPINSKI, E. Ed. (1992): Dictionnaire de la civilisation phénicienne ef punique. Paris.

MARTiN. R. (1971): Recherches sur les Agronomes Latins et leurs conceptions économiques et sociales. París.

MARTIN-KILCHER. S. (1998): “Le Vin dans la Colonia lulia Karthago". El Vi a l'Antiguitat. Economia, Producció i Comerç al Mediterrani Occidental. Actas II Col-loqui Internacional d'Arqueologia Romana. Badalona; págs. 511-527.

MOREL. J.P. (1998): “Que Buvaient les Carthaginois?». El Vi a l'Antiguitat. Economia, Producció i Comerç al Mediterrani Occidental. Actas II Col-loqui Internacional d'Arqueologia Romana. Badalona; págs. 29-38.

PiCARD. G. Ch. y C. Ch. (1958): La vie quotidienne à Carthage. París.

prados Martinez, F.

- 2000: "La Arqueología Púnica. El descubrimiento de una cultura y el nacimiento de una disciplina científica". Arqueologia Peninsular. História, Teoria e Prática. Actas do $3 .^{\circ}$ Congresso de Arqueologia Peninsular, Vol. 1. Oporto; págs. 301-310.

- (e.p.): “¿Almacenes o centros redistribuidores de carácter sacro? Una reflexión en torno a un modelo arquitectónico tipificado en la Protohistoria mediterránea". Actas II Congreso Internacional de Mundo Púnico, Cartagena 2000. Cartagena.

RUIZ MATA, D. (1995): “El vino en época prerromana en Andalucia occidental». Arqueologia del Vino. Los origenes del vino en Occidente. Jerez de la Frontera.

Ruiz Mata, D. y PERez, C.J. (1995): El Poblado Fenicio del Castillo de Doña Blanca (El Puerto de Santa María, Cádiz). El Puerto de Santa Maria.

SAEZ FERNÁNDEZ, P. (1999): "El vino en las fuentes históricas romanas". El vino en la Antigüedad Romana. Simposio Arqueologia del Vino (Jerez, 1996). Madrid; págs. 35-50.

Sethom, H. (1977): L'Agriculture de la presqu'île du Cap Bon. Túnez. 
SETHOM. H. y KASSAB, A. (1981): Les Régions geógraphiques de la Tunisie. Túnez.

TLATI. S-E. (1978): La Carthage Punique. Túnez.

Trousset, P. (1995): (Ed.) L'Afrique du Nord antique et Médiévale. Productions et exportations africaines. Actualités archéologiques (Vle Colloque International sur l'Histoire et l'Archéologie de l'Afrique du Nord, Pau, 1993). París.

VANDERMERSCH. CH. (1994): Vins et amphores de Grande Grèce et de Sicile. IVe- IIle s. avant J.-C. Nápoles.

VV.AA. (1979): Byrsa 1. Rapports préliminares des fouilles 1974-1976. Ecole française de Rome. Roma.

VV.AA. (1982): Byrsa II. Mission archéologique française à Carthage. Ecole Française de Rome. Roma.

ZOHARY, D. (1996): «The domestication of the gravepine Vitis Vinifera L. in the Near East». En Mc Govern, P.E., Fleming, S.J. y Katz, S.H. (Eds.) The Origins and ancient history of Wine. Amsterdam; págs. 23-30.

ZEIST, W van y BOTTEMA, S. (1982): "Paleobotanical studies of Carthage". Bulletin de Centre d'étude et documentation archéologique de la conservation de Carthage 5; págs. 18-22. París. 